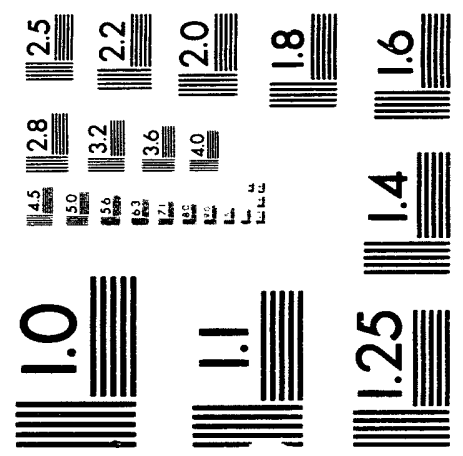






\section{DISCLAIMER}

This report was prepared as an account of work sponsored by an agency of the United States Government. Neither the United States Government nor any agency thereof, nor any of their Goves or implied, or assumes any legal liability or respons employes, maks any watus, product, or bility for the accuracy, completeness, or usefulness of any in privately owned rights. Referprocess disclosed, or represents that its use would not infringe privately owned rights. Reference herein to any specific commercial product, process, or service by trade name, trademark, manucturer, or otherwise does not necessarily constitute or imply its endorsement, recommention mendathe of the United States Government or any agency thereof.

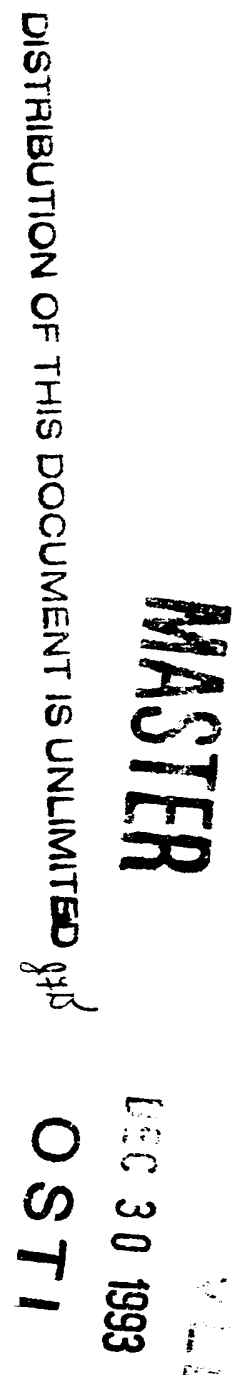

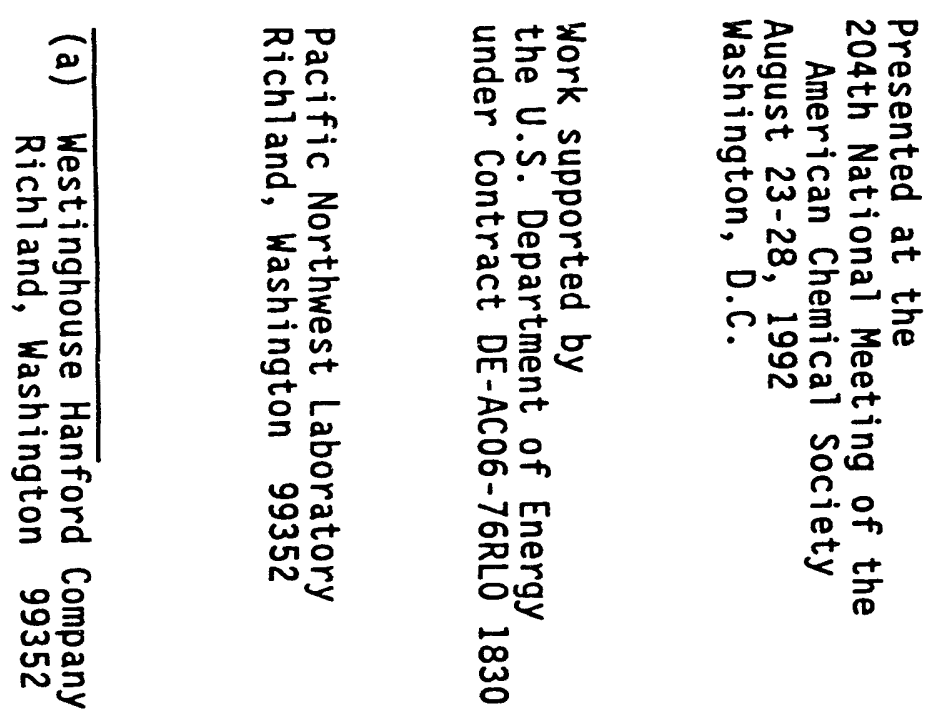

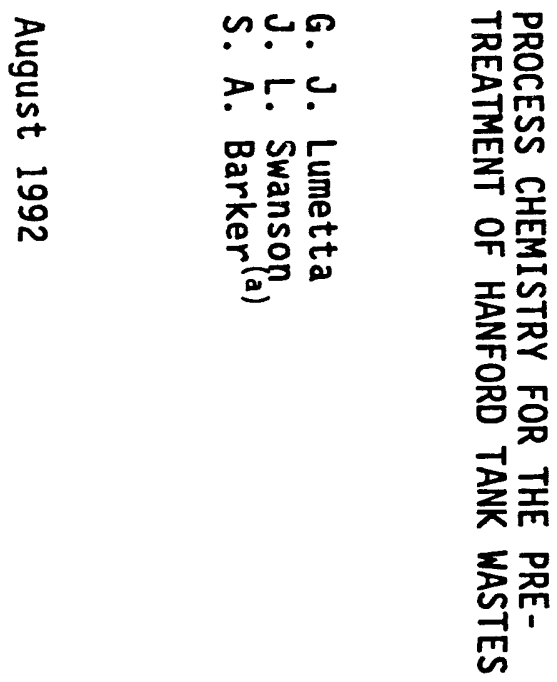

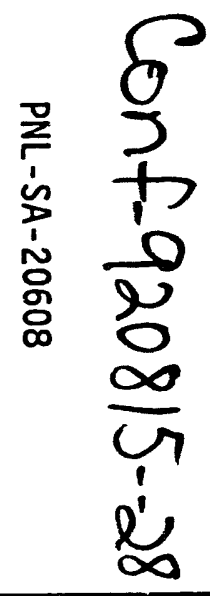




\title{
PROCESS CHEMISTRY FOR THE PRETREATMENT OF HANFORD TANK WASTES
}

\author{
Gregg J. Lumetta and John L. Swanson \\ Pacific Northwest Laboratory ${ }^{(a)}$ \\ Richland, Washington 99352 \\ and \\ Steven A. Barker \\ Westinghouse Hanford Company \\ Richland, Washington 99352
}

\begin{abstract}
Current guidelines for disposing radioactive wastes stored in underground tanks at the U.S. Department of Energy's Hanford Site call for the vitrification of high-level waste in borosilicate glass and disposal of the glass canisters in a deep geologic repository. Low-level waste is to be cast in grout and disposed of on site in shallow burial vaults. Because of the high cost of vitrification and geologic disposal, methods are currently being developed to minimize the volume of high-level waste requiring disposal.

Two approaches are being considered for pretreating radioactive tank sludges: 1) leaching of selected components from the sludge and 2) acid dissolution of the sludge followed by separation of key radionuclides. The leaching approach offers the advantage of simplicity, but the acid dissolution/radionuclide extraction approach has the potential to produce the least number of glass canisters.

Four critical components $(\mathrm{Cr}, \mathrm{P}, \mathrm{S}$, and $\mathrm{Al})$ were leached from an actual Hanford tank waste - Plutonium Finishing Plant sludge. The Al, $P$, and $S$ ivere removed from the sludge by digestion of the sludge with $0.1 \mathrm{M} \mathrm{NaOH}$ at $100^{\circ} \mathrm{C}$. The $\mathrm{Cr}$ was leached by treating the sludge with alkaline $\mathrm{KMnO}_{4}$ at $100^{\circ} \mathrm{C}$. Removing these four components from the sludge will dramatically lower the number of glass canisters required to dispose of this waste.

The transuranic extraction (TRUEX) solvent extraction process has been demonstrated at a bench scale using an actual Hanford tank waste. The process, which involves extraction of the transuranic elements with octyl(phenyl) $\mathrm{N}, \mathrm{N}$ diisobutylcarbamoylmethylphosphine oxide (CMPO), separated $99.9 \%$ of the transuranic
\end{abstract}

(a) Pacific Northwest Laboratory is operated for the U.S. Department of Energy by Battelle Memorial Institute under Contract DE-AC06-76RLO 1830. 
elements from the bulk components of the waste. Several problems associated with the TRUEX processing of this waste have been addressed and solved.

\section{INTRODUCTION}

Methods are being developed to treat and dispose of large volumes of radioactive wastes stored in underground tanks at the U.S. Department of Energy's (DOE) Hanford Site. Under current guidelines, the high-level waste (HLW) will be vitrified into borosilicate glass and disposed of in a geologic repository, while the low-level waste (LLW) will be converted to grout and disposed of by shallow burial on the Hanford Site. Because of the high cost of vitrification and geologic disposal, pretreatment methods are being developed to minimize the volume of HLW requiring disposal.

In this paper, we discuss two general approaches that are being considered for pretreating Hanford tank sludges. In the first approach, critical components are leached from the sludges while leaving the transuranic (TRU) elements in the sludge. In the second approach, acid dissolution of the sludges is followed by separating the TRU elements from the bulk sludge compentents using the transuranic extraction (TRUEX) process $(1,2,3) .^{(b)}$

The plant that is to be used to vitrify HLW at Hanford utilizes a liquid-fed ceramic melter. Certain elements in the vitrification feed cause problems in operating the melter. For example, $\mathrm{Cr}$ can form an undesirable crystalline phase which can cause problems in operating the vitrification plant. Thus, the limits for $\mathrm{Cr}$ in the vitrification feed are low.

For any given waste, a critical component is present that defines the minimum number of glass canisters required to dispose of that waste. In the case of Hanford Plutonium Finishing Plant (PFP) sludge, ${ }^{(c)}$ the critical component is $\mathrm{Cr}$. The next critical

(b) Depending on the composition of the waste and the specifications for the LLW form, additional radionuclides (e.g., ${ }^{90} \mathrm{Sr}$ ) might also need to be removed.

(c) The PFP sludge consists of the neutralized raffinate from a tributyl phosphate (TBP) extraction process for recovering Pu from scrap materials. This process was conducted in the Plutonium Finishing Plant at Hanford. Miscellaneous other 
component is $\mathrm{P}$; that is, if the $\mathrm{Cr}$ were removed from this sludge, $\mathrm{P}$ would become the limiting component. The third and fourth critical components are $S$ and $A l$, respectively. Removing the critical component results in lowering the number of glass canisters required to dispose of the waste (Table 1). Methods to leach these four components from PFP sludge will be described in this paper.

An alternative approach to the pretreatment of Hanford tank sludges is to dissolve the sludge in acid and separate the relatively small amount of TRU elements present from the bulk sludge components. ${ }^{(a)}$ The TRUEX process is being developed for this purpose $(1,2,3)$. This process is a solvent exiraction process in which the TRUs are extracted from nitric acid solution using octyl(phenyl)-N,N-diisobutylcarbamoylmethylphosphine oxide (CMPO). In this paper, we will discuss the TRUEX processing of another unique Hanford waste - neutralized cladding removal waste (NCRW) sludge. ${ }^{\text {(d) }}$

\section{EXPERIMENTAL}

\section{Leaching of PFP Sludge}

A $0.65 \mathrm{~g}$ sample of PFP sludge was mixed with $5 \mathrm{~mL}$ of $0.1 \mathrm{M} \mathrm{NaOH}$ and the slurry was heated at $100^{\circ} \mathrm{C}$ for $1 \mathrm{~h}$. After cooling, the mixture was centrifuge and the supernatant liquid was decanted. This treatment with $0.1 \mathrm{M} \mathrm{NaOH}$ was repeated three more times.

The PFP sludge was then mixed with $10 \mathrm{~mL} 0.014 \mathrm{M} \mathrm{KMnO}_{4}$ in $0.1 \underline{\mathrm{M} \mathrm{NaOH}}$ at $100^{\circ} \mathrm{C}$ for $1 \mathrm{~h}$. After cooling, the mixture was centrifuged and the leach solution was

wastes have also been added to the tank containing this sludge. The sludge consists primarily of $\mathrm{Fe}, \mathrm{Al}, \mathrm{Cr}, \mathrm{Mn}$, and $\mathrm{Ca}$ oxides/hydroxides contaminated with TRUs and various fission products.

(d)

NCRW sludge was formed by the neutralization of the solution formed by chemical decladding of Zircaloy-clad metallic uranium fuel by the Zirflex Process (4). The sludge consists primarilly of $\mathrm{Zr}(\mathrm{OH})_{4}$ and $\mathrm{NaF}$. It also contains $\mathrm{U}$, TRUs (Am $+\mathrm{Pu}$ $\sim 1000 \mathrm{nCi} / \mathrm{g}$ sludge), and mixed fission products $\left({ }^{137} \mathrm{Cs},{ }^{90} \mathrm{Sr},{ }^{126} \mathrm{Sb}\right.$, etc.). 
decanted. The leached sludge was dissolved for analysis by heating at $100^{\circ} \mathrm{C}$ with 13.5 $\mathrm{mL} 1.8 \mathrm{M} \mathrm{HCl} / 1.1 \mathrm{M} \mathrm{HF}$.

All of the solutions were analyzed for $\mathrm{Al}, \mathrm{Cr}, \mathrm{Fe}$, and $\mathrm{P}$ by inductively coupled plasma atomic emission spectroscopy (ICP). Ion chromatographic analyses were done to determine the $\mathrm{PO}_{4}{ }^{3 \cdot}$ and $\mathrm{SO}_{4}{ }^{2 \cdot}$ content of each solution.

\section{TRUEX Processing of NCRW Sludge}

A $2.45 \mathrm{~g}$ portion of NCRW sludge was slurried with $19 \mathrm{~mL}$ of water. Nitric acid $(3.8 \mathrm{~mL}$ of $15.7 \mathrm{M})$ was added dropwise with stirring. After the last addition of $\mathrm{HNO}_{3}$, the mixture was stirred for $2 \mathrm{~h}$ at room temperature. The dissolved NCRW sludge solution was clarified by filtration through a $0.2-\mu \mathrm{m}$ membrane filter.

To prepare the feed for the solvent extraction process, $8.33 \mathrm{~mL}$ of water and 0.63 $\mathrm{mL}$ of $15.7 \mathrm{M} \mathrm{HNO}_{3}$ were added to $15.0 \mathrm{~mL}$ of the dissolved NCRW sludge solution. After $0.35 \mathrm{~mL}$ of this solution was removed for various analyses, $0.24 \mathrm{~mL}$ of $1 \mathrm{M} \mathrm{H}_{2} \mathrm{C}_{2} \mathrm{O}_{4}$ was added to complete preparation of the aqueous phase for the first extraction contact. This solution represented a blend of the feed solution and the three scrub streams shown in Figure 1.

The TRUEX solvent used consisted of $0.2 \mathrm{M}$ CMPO plus $1.4 \mathrm{M}$ tri-n-butyl phospate (TBP) dissolved in a normal paraffin hydrocarbon (NPH). It was washed with aqueous carbonate solution prior to use.

Eight milliliters of the TRUEX solvent was mixed with $24 \mathrm{~mL}$ of the feed solution for 30 seconds. The mixture was centrifuged to ensure separation of the two phases. Portions of both the organic and aqueous phases were subjected to additional contacts as summarized in Table 2.

The concentrations of nonradioactive metal ions were determined by ICP analysis. Analyses for alpha-emitting radionuclides involved counting $0.1-\mathrm{mL}$ dried mounts of diluted samples from the aqueous phase of each contact. Concentrations of the various components in the organic phases were calculated by mass balance. Total fluoride concentrations. were determined potentiometrically using a fluoride-selective electrode, 
and acid content was determined by potentiometric titration with standard $\mathrm{NaOH}$. The acid concentrations reported in this paper represent the concentration of $\mathrm{HNO}_{3}+\mathrm{HF}$. The endpoints of the titrations were taken to be at $\mathrm{pH} 7$, and the acid concentrations were corrected for the contribution of hydrolyzable ions using the following equation: $\left[\mathrm{H}^{+}\right]=$ $\left[\mathrm{H}^{+}\right]_{\text {total }}-2[\mathrm{Zr}]-3([\mathrm{Al}]+[\mathrm{Fe}]+[\mathrm{Cr}])$.

\section{RESULTS AND DISCUSSION}

\section{Leaching of PFP Sludge}

When a portion of PFP sludge was digested with $0.1 \mathrm{M} \mathrm{NaOH}$ at $100^{\circ} \mathrm{C}$, virtually all of the $\mathrm{PO}_{4}{ }^{3 \cdot}$ and $\mathrm{SO}_{4}{ }^{2 \cdot}$, and most of the $\mathrm{Al}$, was removed from the sludge (Table 3 ). A fraction $(27.1 \%)$ of the $\mathrm{Cr}$ originally present in the sludge was also removed by this treatment. This portion of the $\mathrm{Cr}$ was present as $\mathrm{CrO}_{4}{ }^{2-}$ (as determined spectrophotometrically), so it was readily soluble in $0.1 \mathrm{M} \mathrm{NaOH}$. The remaining $\mathrm{Cr}$ in the sludge was in the +3 oxidation state; thus, to leach the remaining $\mathrm{Cr}$ from the sludge it was oxidized to $\mathrm{CrO}_{4}{ }^{2}$ with $\mathrm{KMnO}_{4}$.

The oxidation of $\mathrm{Cr}(\mathrm{III})$ to $\mathrm{Cr}(\mathrm{VII})$ with $\mathrm{MnO}_{4}$ proceeds in basic solution according to the following equation:

$$
\mathrm{Cr}(\mathrm{OH})_{3}+\mathrm{MnO}_{4}^{-}+\mathrm{OH}^{-}-\mathrm{CrO}_{4}^{2-}+\mathrm{MnO}_{2}+2 \mathrm{H}_{2} \mathrm{O} \quad \epsilon^{\circ}=+0.72 \mathrm{~V}
$$

For every mole of $\mathrm{Cr}$ leached from the sludge, one mole of $\mathrm{Mn}$ is added to the sludge in the form of $\mathrm{MnO}_{2}$. The addition of $\mathrm{Mn}$ to the sludge is acceptable because the limit for $\mathrm{Mn}$ in the vitrification feed is ten times the limit for $\mathrm{Cr}$. However, by using $\mathrm{MnO}_{4}{ }^{-}$to leach $\mathrm{Cr}, \mathrm{Mn}$ becomes the critical component in the waste. It is estimated that if $\mathrm{Al}, \mathrm{P}$, and $\mathrm{S}$ were removed by digestion in dilute $\mathrm{NaOH}$, and $\mathrm{Cr}$ was removed by leaching with $\mathrm{MnO}_{4}{ }^{2}$, 420 canisters of glass would be required to dispose of the PFP sludge. This number could be lowered to approximately 300 canisters (Table 1) if a different oxidant were used. We are currently evaluating alternative oxidants for this purpose. 
If the PFP sludge is pretreated using the TRUEX process, it is expected that the number of glass canisters required to dispose of the TRU fraction of the waste will be defined by the amount of the sludge that does not dissolve in $\mathrm{HNO}_{3}$. Dissolution tests conducted in our laboratory suggest that approximately 100 canisters would be required if the PFP sludge were dissolved and processed using TRUEX. Thus, the TRUEX approach would result in a smaller number of glass canisters being produced from PFP sludge than would the leaching approach. However, the TRUEX process would be much more difficult to implement than the simple leaching methods described here.

\section{TRUEX Processing of NCRW Sludge}

The flowsheet describing the experiment performed to test an early concept for the TRUEX processing of NCRW sludge is shown in Figure 1. The experiment done to test this flowsheet consisted of the following steps: 1) sludge dissolution and solution clarification by filtration, 2) adjustment of the solution so that it represented a blend of the feed and the three scrub streams shown in Figure 1, 3) extraction, 4) scrubbing (with three different streams), and 5) stripping. The functions of the three scrub streams were to 1) remove extracted $\mathrm{Zr}$ and $\mathrm{F}$ with aqueous $\mathrm{H}_{2} \mathrm{C}_{2} \mathrm{O}_{4}$, 2) remove extracted $\mathrm{H}_{2} \mathrm{C}_{2} \mathrm{O}_{4}$ with $\mathrm{HNO}_{3}$, and 3) remove extracted $\mathrm{HNO}_{3}$ with water.

Unwashed NCRW sludge dissolved readily in dilute $\mathrm{HNO}_{3}$. In the treatment with $\mathrm{HNO}_{3}, 97.8 \%$ of the $\mathrm{Zr}$ and virtually $100 \%$ of the Na dissolved. Significant amounts of $\mathrm{Al}$ (25\%) and $\mathrm{P}(43 \%)$ did not dissolve in $\mathrm{HNO}_{3}$. The adjusted feed solution consisted of $0.10 \underline{\mathrm{M} \mathrm{Zr}}, 1.14 \underline{\mathrm{M} \mathrm{Na}}, 0.049 \underline{\mathrm{M} \mathrm{K}}, 0.045 \underline{\mathrm{M} \mathrm{Al}}, 0.035 \mathrm{M} \mathrm{Si}, 0.004 \underline{\mathrm{M} \mathrm{U}}, 0.37 \underline{\mathrm{M}} \mathrm{F}$, and 1.68 $\underline{\mathrm{M} \mathrm{H}} \mathrm{H}^{+}$. The feed solution also contained $62.0 \mathrm{nCi} / \mathrm{mL} \mathrm{Pu}$ and $9.5 \mathrm{nCi} / \mathrm{mL} \mathrm{Am}$.

The results of the extraction contacts are shown in Figure 2. The TRUs were effectively extracted from the dissolved NCRW solution. The distribution coefficients for the TRUs in the first and second extractions were 69 and 34, respecively; and that for the third extraction contact was approximately 6 . The raffinate from the third extraction contained only $0.1 \%$ of the TRU activity originally present in the feed. A significant 
amount of $\mathrm{Zr}$ was extracted, but $\mathrm{Na}$ and $\mathrm{Al}$ were not. As expected from published data (1), a large fraction of the $\mathrm{HNO}_{3}$ was extracted.

The small portion of $\mathrm{Zr}$ that was extracted was removed from the solvent during the first three scrub contacts (Figure 3). Zirconium could not be detected in solutions from subsequent contacts. Thus, $\mathrm{H}_{2} \mathrm{C}_{2} \mathrm{O}_{4}$ is very effective at removing $\mathrm{Zr}$ from the extact. Of the fluoride that was extracted, $99.3 \%$ was scrubbed out after the sixth scrub contact; the data in Figure 3 suggest that the residual $F^{-}$may be difficult to remove from the extract. The results from scrubs five and six indicate that water can lower the acid content of the extract. Throughout the six scrub contacts, the TRUs remained in the organic phase.

The TRUs were efficiently stripped fromi the scrubbed extract (Figure 4) with 1-Hydroxyethane-1,1-diphosphonic acid (HEDPA). Over $99 \%$ of the TRUs were stripped in the first strip contact. The amount of TRUs present after the third strip was below detection limits.

These results serve as proof-of-principle that the TRUEX process can be used to separate TRUs from the bulk components ( $\mathrm{Zr}$ and $\mathrm{Na}$ ) of NCRW sludge. The extraction of the TRUs was very good; only $\sim 0.1 \mathrm{nCi} / \mathrm{mL}$ of alpha activity remained in the aqueous phase after the third extraction. Good separation of the alpha-emitting radionuclides from most nonradioactive materials was achieved. For example, the feed solution contained $\sim 7800 \mathrm{nCi}$ TRU per $\mathrm{g}$ of $\mathrm{Zr}$, but the aqueous phase from the third extraction contained only $11 \mathrm{nCi}$ per $\mathrm{g} \mathrm{Zr}$. Likewise, the feed solution contained $\sim 4400 \mathrm{nCi}$ TRU per $\mathrm{g}$ of $\mathrm{Na}$, whereas the aqueous phase from the third extraction contained only $5 \mathrm{nCi}$ TRU per $\mathrm{g} \mathrm{Na}$. Elements that were not well separated from the alpha emitters were $U$ and the lanthanides (e.g. La, Ce, and Eu). 
However, further study identified some problems with the TRUEX processing of NCRW sludge, such as

- corrosion of stainless steel piping and equipment

- precipitation from dissolved NCRW sludge solutions

- interfacial crud formation in the extraction step

- excessive quantity of HEDPA stripping agent.

Each of these problems has been addressed and solved, as is discussed below.

Originally, it was planned to implement the TRUEX process in an existing facility (B-Plant) at Hanford. Corrosion tests with simulated dissolve NCRW solutions indicated that the imbedded piping in this plant might be susceptible to corrosion during tho TRUEX processing of NCRW sludge. Recently, it has been determined that B-Plant will not be used to process Hanford tank wastes; rather, a new pretreatment facility will be built. Thus, corrosion of piping in B-Plant was rendered a non-problem. Corrosion should not be a problem in the new facility because appropriate alloys will be chosen for construction.

During the course of many experiments with actual NCRW samples, it was discovered that solids formed in dissolved sludge solutions at sporadic intervals, that ranged from weeks to days. The formation of precipitates in the dissolved sludge solution was deemed to be a problem because this would require additional equipment clean-out capability:

In these early experiments, the NCRYV sludge samples were dissolved in $\mathrm{HNO}_{3}$ directly. It was discovered that washing the sludge with water prior to acid dissolution resulted in dissolved sludge solutions that were stable for weeks to months (Table 4). Washing the sludge lowers the $\mathrm{Na}$ and $\mathrm{F}$ content. In order to achieve adequate sludge dissolution, $\mathrm{F}$ must be added during the dissolution step so that the $\mathrm{F} /(\mathrm{Zr}+\mathrm{Al})$ ratio is approximately 2. This can be done by auding $\mathrm{HF}$ along with $\mathrm{HNO}_{3}$ during dissolution. Solutions prepared by dissolving washed NCRW sludge in this manner are sufficiently stable that equipment clean-out capability is not expected to be needed. 
The third problem associated with the TRUEX processing of NCRW sludge was interfacial crud forming during the extraction step. Although no crud was observed in the above described experiment, interfacial crud was observed in some TRUEX experiments with dissolved NCRW solutions. In some cases, the amount of crud was so severe that the entire organic phase was filled with solids.

Further studies revealed that interfacial crud can be controlled by adjusting the $\mathrm{F} /(\mathrm{Zr}+\mathrm{Al})$ ratio in the solvent extraction feed. Figure 5 summarizes the interfacial crud observations from a number of experiments with dissolved NCRW solutions. Solutions were prepared from both washed and unwashed sludges. In all cases, the feed solutions were aged a minimum of $1 \mathrm{~h}$ prior to contacting with the TRUEX solvent; the organic-toaqueous phase ratio was 0.33 in each contact. Although the process conditions have not yet been fully optimized, the data in Figure 5 suggest that the concentration of $\mathrm{Zr}$ in the extraction stages should be maintained below $0.15 \mathrm{M}$ and the $\mathrm{F} /(\mathrm{Zr}+\mathrm{Al})$ ratio greater than 4. The $F /(Z r+A l)$ ratio can be adjusted by additing $H F$ to the dissolved sludge solution. We have observed that increasing the $\mathrm{F} /(\mathrm{Zr}+\mathrm{Al})$ ratio does not have an immediate effect in eliminating interfacial crud, so a lag time of $1 \mathrm{~h}$ should be allowed between adding $\mathrm{HF}$ and beginning the extraction step.

The composition of the interfacial crud has not been determined, but it is presumed to contain a $\mathrm{Zr}$ species. The crud forms when the concentration of this species in the organic phase exceeds its solubility. Complexation of $\mathrm{Zr}$ by $\mathrm{F}$ lowers the distribution coefficient for $\mathrm{Zr}$; thus, raising the $\mathrm{F} /(\mathrm{Zr}+\mathrm{Al})$ decreases the extraction of $\mathrm{Zr}$ and the crud does not form.

The fourth problem with the TRUEX processing of NCRW sludge concerns using $0.2 \mathrm{M}$ HEDPA as the stripping solution. Although this solution performs very well in stripping the TRUs from the extract (Figure 4), the phosphorus content of this solution will cause problems in subsequent processing, namely, in the vitrifying the TRU fraction of the waste. Several alternative stripping solutions have been identified [e.g. sodium citrate, $0.002 \underline{M}$ HEDPA $+0.25 \underline{M} \mathrm{Na}_{2} \mathrm{CO}_{3}(5)$, ferrous sulfamate, etc.]. A final decision has not been made on which strip solution will be used. 


\section{CONCLUSION}

Two different appoaches are being investigated for reducing the quantity of HLW needing disposal at the Hanford Site. Selective leaching of glass-limiting components is a method applicable in selected cases and is easy to implement. Simple methods have been demonstrated for leaching $\mathrm{Cr}, \mathrm{P}, \mathrm{S}$, and Al from PFP sludge. The second approach--sludge dissolution and extraction of TRUs--is generally applicable and will likely result in a greater reduction in quantity of HLW needing disposal. Batch testing of the TRUEX process on actual NCRW sludge indicates that this process will effectively separate the TRU component of this waste from the bulk sludge materials.

\section{ACKNOWLEDGEMENTS}

Pacific Northwest Laboratory is operated for the U.S. Department of Energy by Battelle Memorial Institute under Contract DE-AC06-76RLO 1830. The authors would like to thank Jeff Deal and Michael Wagner for performing much of the experimental work described in this paper. The assistance of Brian Rapko and Wayne Cosby in reviewing this paper is also gratefully acknowledged.

\section{REFERENCES}

1. Horwitz, E. P.; Kalina, D. G.; Diamond, H.; Vandegrift, G. F.; Schulz, W. W. Solvent Extr. Ion Exch. 1985, 3, 75.

2. Horwitz, E. P.; Schulz, W. W. in Solvent Extraction and lon Exchange in the Nuclear Fuel Cycle; Logsdail, D.H. and Mills, A.L., Eds.; Ellis Horwood: Chichester, 1985; p. 137.

3. Schulz, W. W.; Hon'itz, E. P. Sep. Sci. Technol. 1988, 23, 1191.

4. Swanson, J. L. in Progress in Nuclear Energy Series III: Process Chemistry; Bruce, F. R., Fletcher, J. M., and Hyman, H. H., Eds.; Pergamon Press: New York, 1961; p. 289.

5. Lumetta, G. J.; Swanson, J. L. Sep. Sci. Technol. 1993, $28,43$. 


\section{FIGURE CAPTIONS}

Figure 1. Flowsheet for the pretreatment of NCRW sludge by the TRUEX process.

Figure 2. Results of the extraction contacts in the experiment testing the flowsheet in Figure 1.

Figure 3. Results of the scrub contacts in the experiment testing the flowsheet in Figure 1.

Figure 4. Results of the strippinc contacts in the experiment testing the flowsheet in Figure 1.

Figure 5. Interfacial crud formation in TRUEX contacts with dissolved NCRW sludge. The $\mathrm{F} /(\mathrm{Zr}+\mathrm{Al})$ ratio was adjusted as appropriate by addition of $\mathrm{HF}$ to the aqueous solutions. A minimum of one hour was allowed before contacting with the TRUEX process solvent. 
Table 1. Effect of the Removal of Critical Components from PFP Sludge on the Number of Glass Canisters Required to Dispose of this Waste.

\begin{tabular}{ccc} 
Option & No. of Canisters Needed & Limiting Component \\
\hline Sludge Wash (SW) Only & 2480 & $\mathrm{Cr}$ \\
SW + Cr removal & 1230 & $\mathrm{P}$ \\
SW $+\mathrm{Cr}+\mathrm{P}$ removal & 750 & $\mathrm{~S}$ \\
$\mathrm{SW}+\mathrm{Cr}+\mathrm{P}+\mathrm{S}$ removal & 680 & $\mathrm{Al}$ \\
$\mathrm{SW}+\mathrm{Cr}+\mathrm{P}+\mathrm{S}+\mathrm{Al}$ removal & 300 & Other
\end{tabular}


Table 2. Summary of TRUEX Solvent Extraction Contacts Performed To Test the Flowsheet Depicted in Figure 1.

\begin{tabular}{|c|c|c|c|c|c|}
\hline Contact & Step & Aqueous Phase & Organic Phase & $O / A^{(a)}$ & Organic Vol., $\mathrm{mL}$ \\
\hline A & Extn 1 & Feed $^{(b)}$ & TRUEX Solvent & 0.33 & 8.00 \\
\hline B & Extn 2 & From A & TRUEX Solvent & 0.33 & 1.00 \\
\hline C & Extn 3 & From B & TRUEX Solvent & 0.33 & 0.67 \\
\hline D & Scrub 1 & $1.5 \underline{\mathrm{M} H N O_{3}}+0.05 \underline{\mathrm{M} \mathrm{H}} \mathrm{C}_{2} \mathrm{O}_{4}{ }^{(\mathrm{cl})}$ & From A & 1.00 & 7.00 \\
\hline$E$ & Scrub 2 & $1.5 \underline{\mathrm{M} H N O_{3}}+0.05 \underline{\mathrm{M} \mathrm{H}_{2} \mathrm{C}_{2} \mathrm{O}_{4}}$ & From D & 1.00 & 6.00 \\
\hline$F$ & Scrub 3 & $2.3 \underline{\mathrm{M} \mathrm{HNO}}{ }_{3}^{(\mathrm{d})}$ & From E & 1.50 & 5.00 \\
\hline G & Scrub 4 & $2.3 \underline{\mathrm{MHNO}}$ & From $F$ & 1.50 & 4.00 \\
\hline H & Scrub 5 & Water & From G & 3.00 & 3.50 \\
\hline 1 & Scrub 6 & Water & From $\mathrm{H}$ & 3.00 & 3.00 \\
\hline$J$ & Strip 1 & $0.21 \underline{\mathrm{M}} \mathrm{HEDPA}^{(0)}$ & From 1 & 3.00 & 2.50 \\
\hline K & Strip 2 & $0.21 \underline{\mathrm{M}} \mathrm{HEDPA} \mathrm{A}^{(0)}$ & From J & 3.00 & 2.00 \\
\hline L & Strip 3 & $0.21 \underline{M} H_{E D P A}^{(0)}$ & From $\mathrm{K}$ & 3.00 & 1.50 \\
\hline$M$ & Wash & $0.25 \underline{\mathrm{M} \mathrm{Na}}{ }_{2} \mathrm{CO}_{3}$ & From L & 1.00 & 1.00 \\
\hline
\end{tabular}

(a) $\mathrm{O} / \mathrm{A}=$ Volume of the organic phase divided by the volume of the aqueous phase.

(b) The feed solution was a diluted dissolved NCRW sludge solution (see text).

(c) Composition represents a blend of the three scrub streams shown in Figure 1.

(d) Composition represents a blend of the second and third scrub streams shown in Figure 1.

(e) HEDPA = 1-Hydroxyethane-1,1-diphosphonic acid. 
Table 3. Results from the Leaching of PFP Sludge.

\begin{abstract}
$\%$ in $\mathrm{NaOH}$ wash
$\%$ in $\mathrm{KMnO}_{4}$ leach
\end{abstract}

$\%$ in leached sludge

\begin{tabular}{ccccc} 
Al & $\mathrm{Cr}$ & $\mathrm{P}$ & $\mathrm{S}$ & $\mathrm{Fe}$ \\
\hline 69.1 & 27.1 & 100 & 100 & 0.2 \\
29.8 & 69.3 & 0 & 0 & 0 \\
1.1 & 3.6 & 0 & 0 & 99.8
\end{tabular}


Table 4. Stability of Dissolved Sludge Solutions Toward Precipitation.

\begin{tabular}{cccccc}
$Z r, \underline{M}$ & $\mathrm{Al}, \underline{\mathrm{M}}$ & $\mathrm{Na}, \underline{\mathrm{M}}$ & $\mathrm{H}^{+}, \underline{M}$ & $\mathrm{~F} /(\mathrm{Zr}+\mathrm{Al})$ & Days Stable \\
\hline Unwashed Sludge: & & & & & \\
0.24 & 0.053 & 1.78 & 0.6 & 2.9 & $>1,<2$ \\
0.10 & 0.023 & 0.76 & 1.4 & 2.9 & $>1,<2$ \\
0.13 & 0.015 & 1.75 & 1.2 & 2.0 & $>20$ \\
Washed Sludge: & & & & & \\
0.18 & 0.006 & 0.20 & 1.7 & 1.8 & $>170$ \\
0.16 & 0.002 & 0.07 & 1.7 & 2.3 & $>5,<34$ \\
0.13 & 0.011 & 0.06 & 1.8 & 2.5 & $>225$ \\
0.12 & 0.001 & 0.05 & 1.5 & 1.3 & $>150$
\end{tabular}



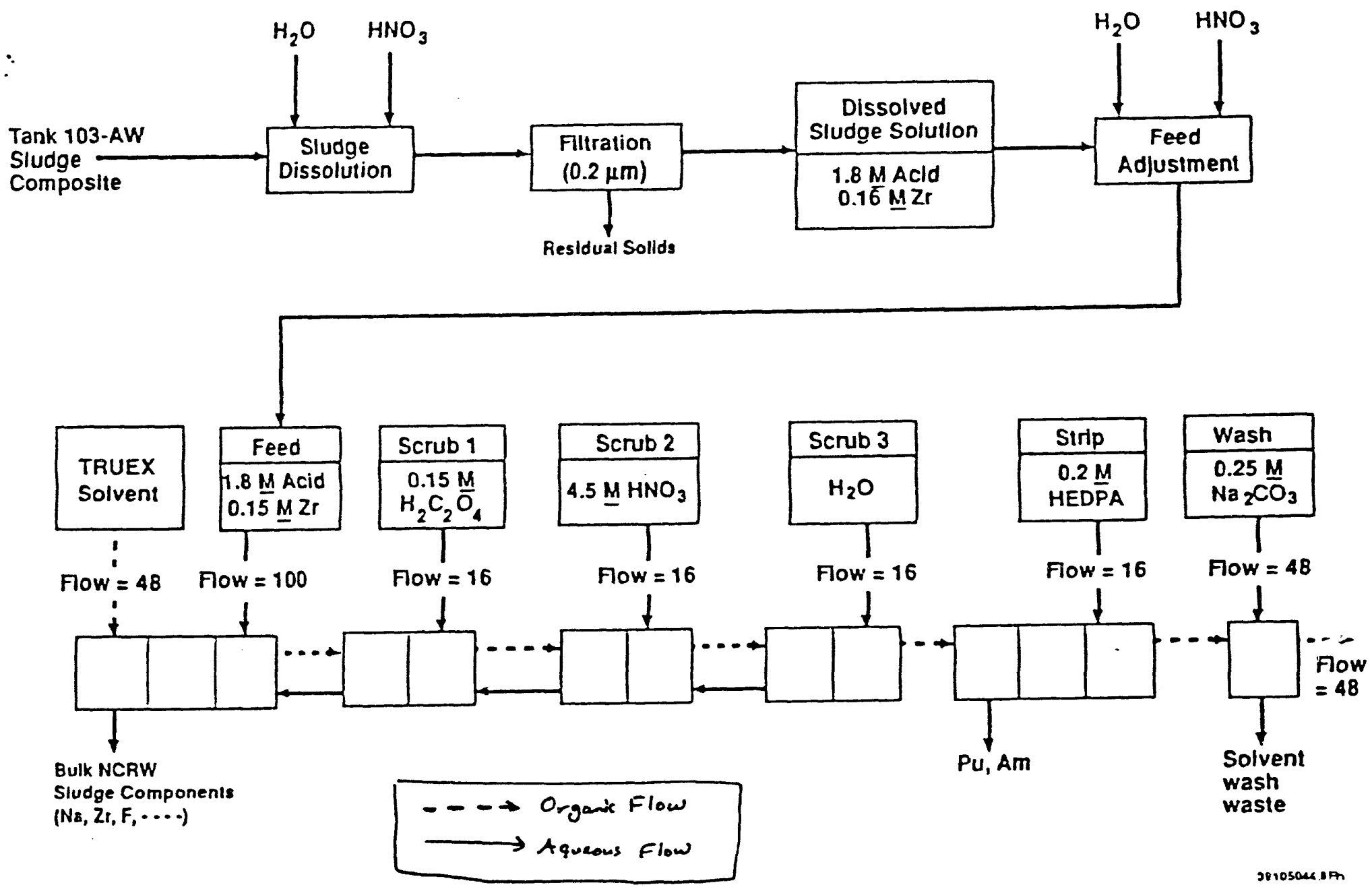

nocian Racic Eynoriment

$$
\begin{aligned}
\text { Fig. Note: Figure is at graphis arts } \\
\text { for modification - will get } \\
\text { ploto medy copy soon. } \sim \text { Jam } 15,1903
\end{aligned}
$$




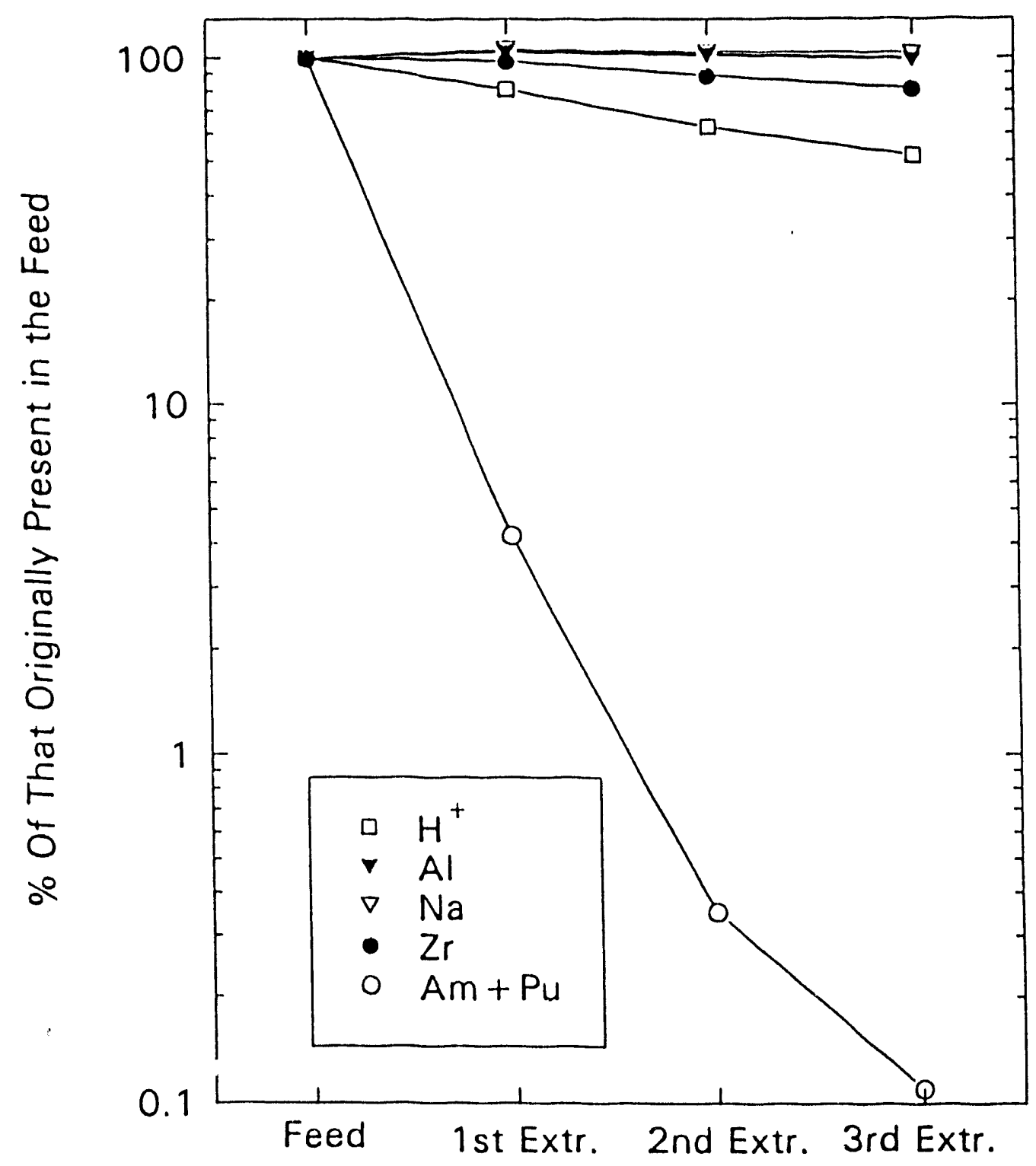

Fig $^{2}$ 


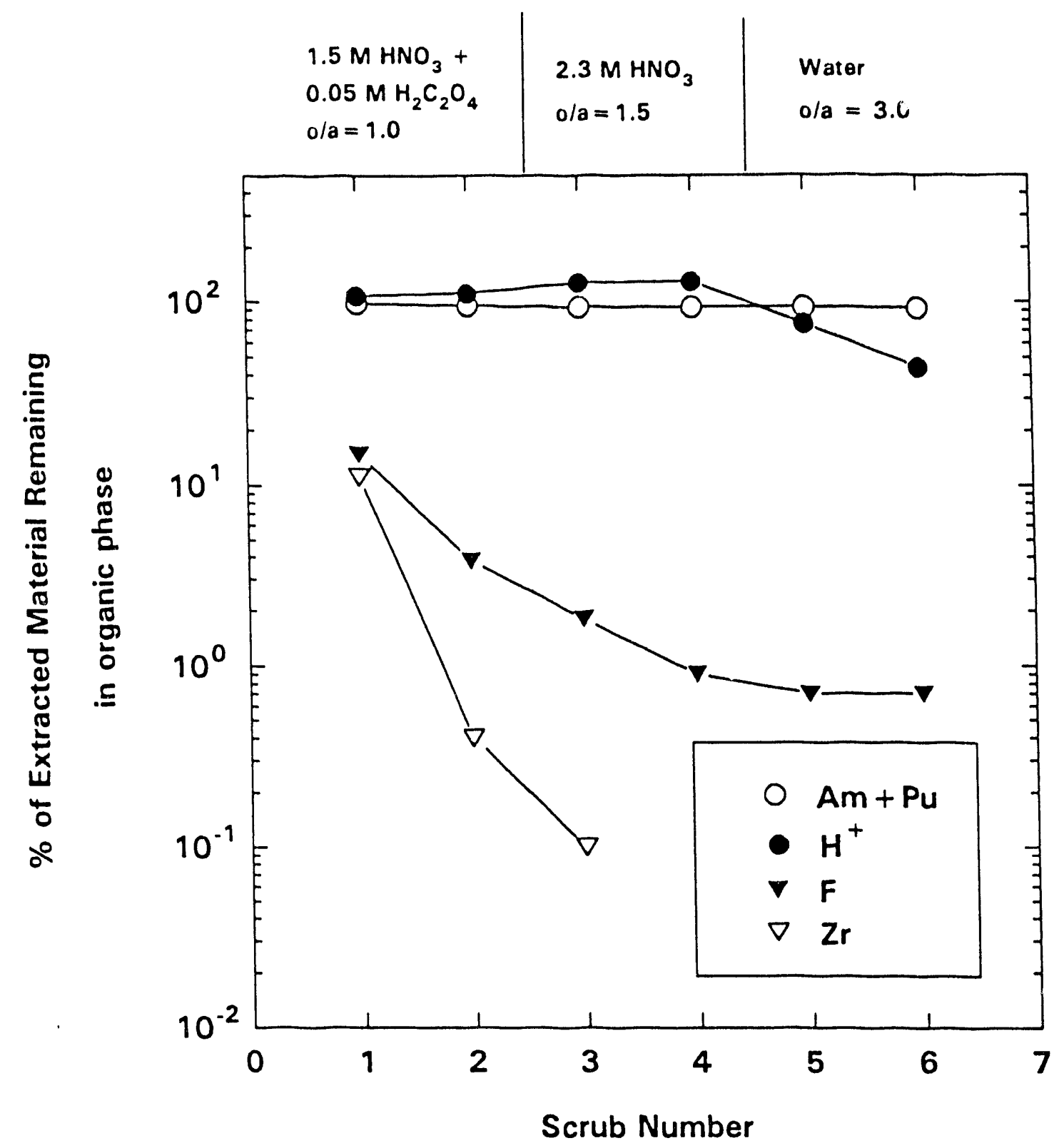




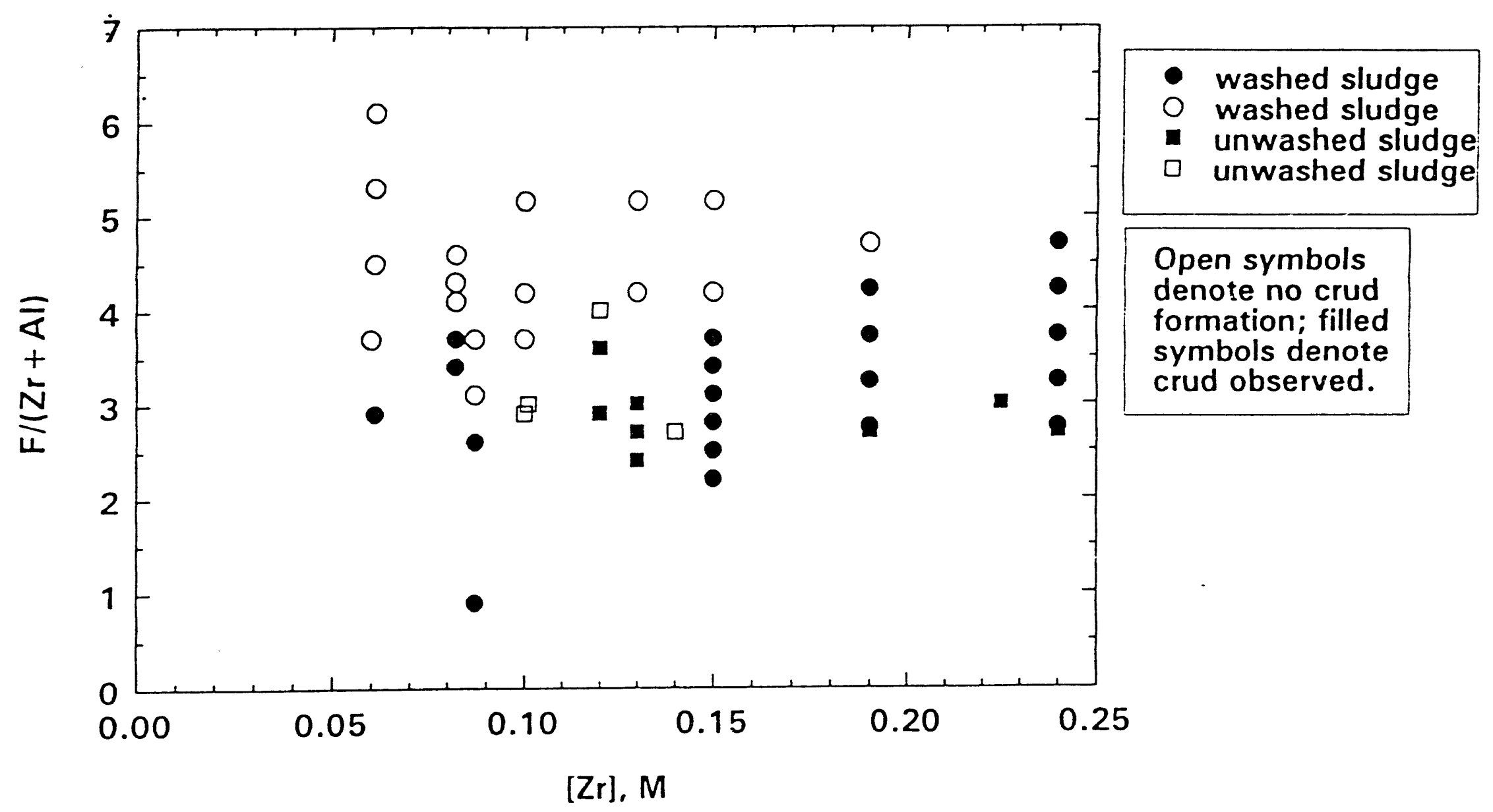

Fig 5 

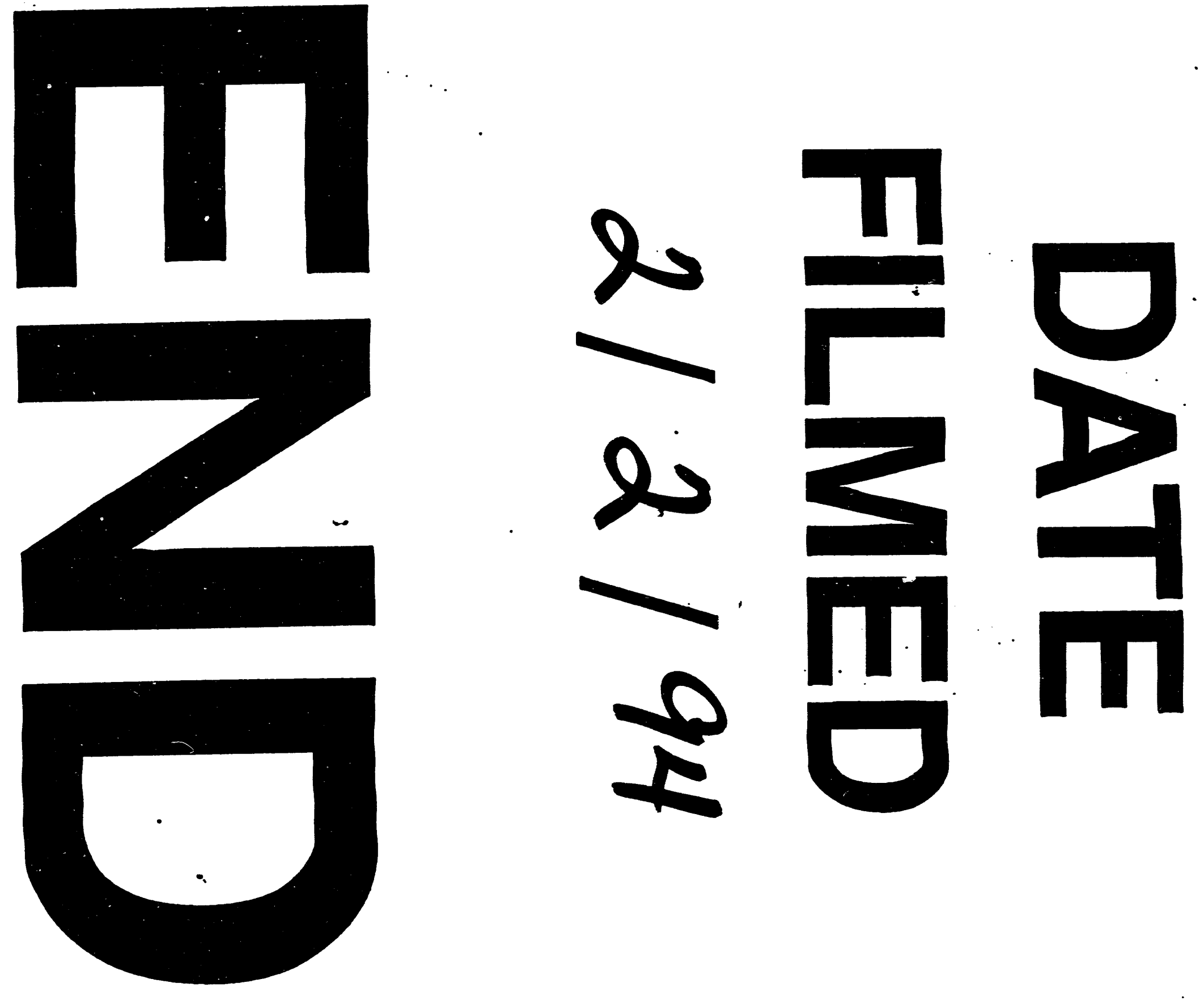
